\title{
Draft Genome Sequence of a Haloalkaliphilic archaeon: Natrialba sp. SSL1 (ATCC 43988) Isolated from Sambhar Salt Lake, India
}

\author{
G.N. Kalambe ${ }^{1}$, P.M. Chandarana ${ }^{2}$, V.M. Tanavade ${ }^{2,3,4}$ and V.N. Upasani $^{5 *}$ \\ ${ }^{1}$ JJTU, Vidyanagari, Jhunjhunu-333001, Rajasthan, India \\ ${ }^{2}$ IBioAnalysis Pvt. Ltd., Ahmedabad 380009, Gujarat, India \\ ${ }^{3}$ Division of Biological \& Life Sciences, School of Arts \& Sciences, Ahmedabad University, \\ Ahmedabad 380009, Gujarat, India \\ ${ }^{4}$ Bioinformatics Institute, Agency for Science Technology \& Research (A*STAR), 30 Biopolis \\ Street, Singapore 138671 \\ ${ }^{5}$ Department of Microbiology, M. G. Science Institute, Ahmedabad 380009, Gujarat, India \\ *Corresponding author: vnu_halophiles@yahoo.com
}

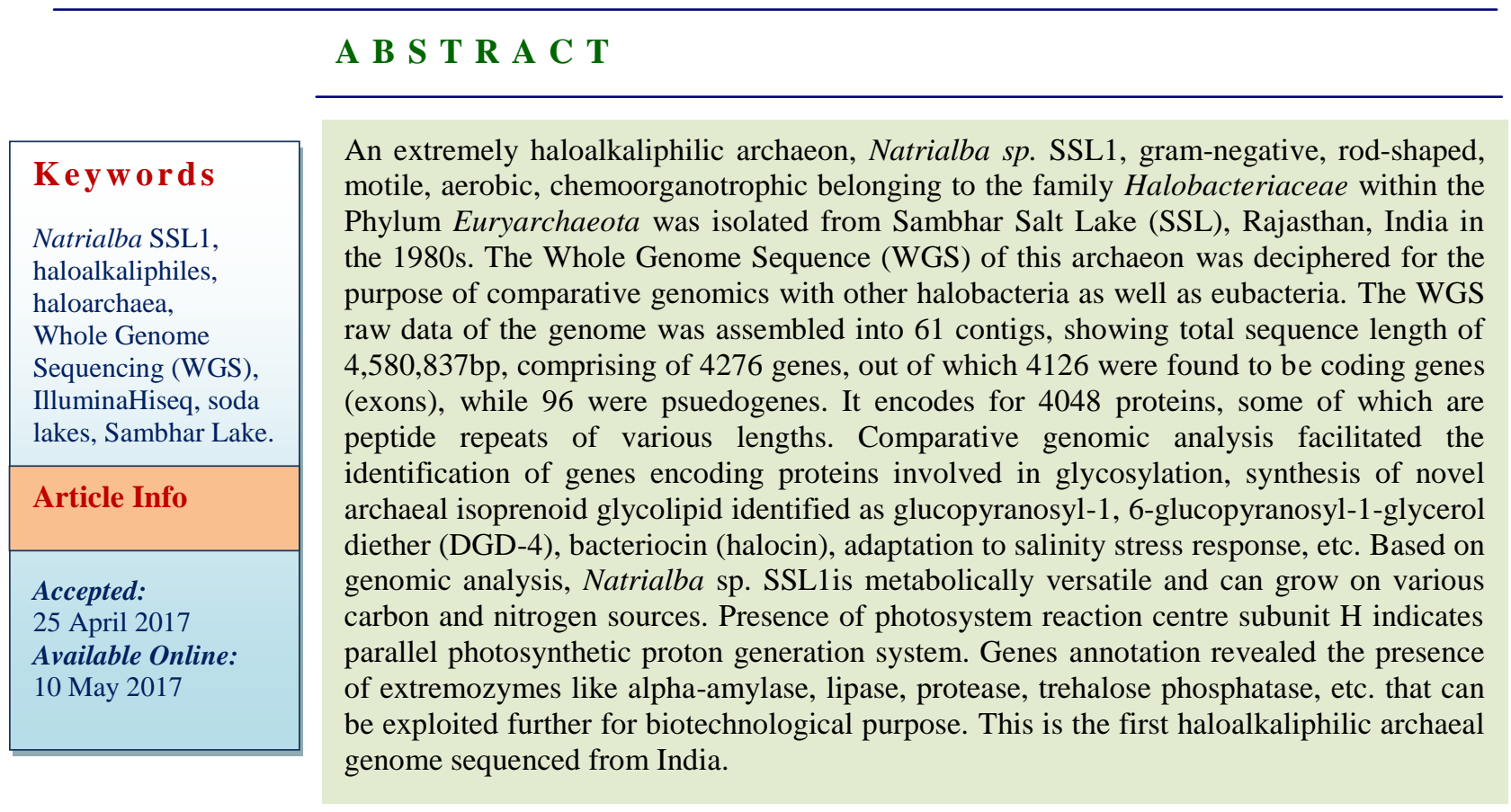

\section{Introduction}

The extremely halophilic archaea belonging to the family Halobacteriaceae (Phylum Euryarchaeota) are commonly found in the hypersaline environments such as salt lakes, salt ponds, marine salterns and soda lakes. Haloarchaea living in such harsh environment copes up with salinity stress by higher intracellular $\mathrm{KCl}$ concentration and synthesis of compatible solutes such as glycerol and glycine betaine.

Some methanogens also belong to the group haloarchaea. The haloalkaliphilic archaea survive in an environment with two 
extremities, namely, high $\mathrm{pH}(>9.0)$ and salt concentration $(>3.0 \mathrm{M} \mathrm{NaCl})$. They adapt to extreme environments by deciphering acidic protein machineries, respiratory chains, rhodopsins, and considerably different metabolism as compared to that of eubacteria (Kennedy et al., 2001; Sreeramulu et al., 1998; Berquist et al., 2005). All halobacteria examined possess ether linked lipids instead of ester linked lipids (present in eubacteria and eukaryotes), which are based on the lipid core 2, 3-di-O-phytanyl-sn-glycerol $\left(\mathrm{C}_{20^{-}} \mathrm{C}_{20^{-}}\right.$ diether). Extreme haloalkaliphiles also possess 2-0-sesterterpanyl-3-0-phytanyl-snglycerol $\left(\mathrm{C}_{20}-\mathrm{C}_{25}\right.$-diether), and 2, 3-di-0sesterterpanyl-sn-glycerol $\quad\left(\mathrm{C}_{25}\right.$ - $\mathrm{C}_{25}$-diether $)$ lipid cores (Kates, 1993; Falb et al., 2005).

The genus Natrialba as per Bergey's Manual of Systematic Bacteriology, vol. I, (2001) belongs to the family Halobacteriaceae. It has been reclassified within the novel order Natrialbales and family Natrialbaceae (Gupta et al., 2015). The recognized species within this genus is summarized in Table 1. It is a heterogeneous group able to survive in neutral as well as alkaline environments. A nonalkaliphilic ( $\mathrm{pH}$ of 6.6 to 7.0) species Natrialba asiatica was isolated from the beach sand, Japan (10). Nab. magadii is an extremely halolalkaliphilic species that was isolated from Lake Magadi, Kenya that grows at $\mathrm{pH} 10.0,20-25(\% \mathrm{w} / \mathrm{v} \mathrm{NaCl})$ and utilizes various range of carbohydrate and noncarbohydrate substrates. Two novel haloalkaliphilic archaea Nab. hulunbeirensis and Nab. chahannaoensis have been isolated from soda lakes in inner Mongolia Autonomous Region, China (Ventosa, 2006). There are seven genomes of species belonging to the genus Natrialba submitted in the NCBI database (October, 2016) namely, Nab. magadii (2), Nab. asiatica (1), Nab. hulunbeirensis (1), Nab. chahannaoensis (1), Nab. aegyptia (1), Nab. taiwanensis (1). However, none was reported for an isolate from India. So, we carried out the whole genome sequence (WGS) of Natrialba SSL1 ATCC 43988 strain isolated from Sambhar Lake, India. Comparative genomic studies with other halophilic as well as haloalkaliphilic archaea has revealed some interesting information that could be useful for future research.

\section{Materials and Methods}

Organism and growth conditions: The haloalkaliphilic archaeal isolate Natrialba SSL1 (ATCC 43988) was isolated from Sambhar Salt Lake situated (Longitude $75^{\circ} 05^{\text {, }}$ E; Latitude $26^{\circ} 58^{\prime} \mathrm{N}$ ) middle of the closed depression in the Aravali schist in Rajasthan, India (Figure 1). The isolate was grown at $37^{\circ} \mathrm{C}$ in modified Brown medium.

\section{Isolation of genomic DNA}

The biomass of the Natrialba strain was obtained by centrifugation at $10,000 \mathrm{rpm}$ at 5 $10^{\circ} \mathrm{C}$ from actively growing cells (5-6 days old broth culture). The genomic DNA was isolated by using the Chromus Biotech bacterial gDNA isolation kit as per the protocol provided in the manual. The quality and quantity of gDNA obtained was determined with UV-Vis spectrophotometry at 260 and $280 \mathrm{~nm}$ (Tindall et al., 1984).

\section{Phylogenetic analysis}

The 16S rDNA was amplified by PCR method of Emble (Emble, 1991), as modified by McGenity and Grant (McGenity et al., 1998). The forward amplification primer was: 27F, TCCGGTTGATCCTGCCGGAG (positions 8-27), and the reverse amplification primer was: 1525R, AAGGAGGTGATCCAGCC (positions 1541-1525) and sequenced at Chromus Biotech Limited, Bangalore. The sequence was deposited in GenBank with accession no. D88256.1. Similar sequence homologs were 
obtained by BLAST search and the phylogenetic tree was constructed by MEGA6.

\section{Whole genome sequencing (WGS)}

The WGS was carried out using the Next generation sequencing (NGS) technology using Illumina Hiseq sequencer. The gDNA sample of Natrialba SSL1 was subjected for genomic library preparation denoted as VUKGS01_1 Prokaryote TN1601D0815 and VUKGS01_2 Prokaryote TN1601 D0816.The raw data/reads obtained were further analysed as per the pipeline given by THERAGEN ETEX Bioinstitute, Korea.

\section{Genome Sequencing and Raw Reads Output}

The raw reads were processed by MyPro (Liao et al., 2015) for sequence assembly. The assembled genome consisting of 61 contigs was submitted to GenBank (NCBI), and annotated by PGAP (Prokaryotic Genome Annotation Pipeline, https://www.ncbi.nlm.nih.gov/genome/annota tion_prok/).

\section{Results and Discussion}

We have isolated and characterized several haloarchaeal strains from Sambhar Lake, Rajasthan having saline and alkaline waters. The isolates have been identified based on morphological, cultural, physiological and $16 \mathrm{~S}$ rRNA sequence homology studies. The isolate Natrialba SSL1 ATCC 43988 was one of the first haloarchaeal isolate reported and characterized from this soda lake that produced various hydrolases, bacteriocin, diether lipids, etc. (Upasani et al., 1988; 1990; 2008; 1994). Therefore, it was chosen in this study for WGS and comparative genomics. The phylogenetic tree constructed for the $16 \mathrm{~S}$ rRNA sequence of Natrialba SSL1 GenBank accession no. D88256.1 using MEGA 6 showed identity with Nab. hulunbeirensis X21 (Figure 2). The comparative genomics data from NCBI of the Natrialba species genomes sequenced to date is summarized in Table 2. A total of 1.31 GB Throughput (Raw reads) was recovered out of 12941508 reads. Clean reads obtained were 11925178 (92.15\%); similarly out of 1307092308 total bases, 1197576003 (91.62\%) clean bases were obtained. The genome $(4.58 \mathrm{Mb})$ was assembled into 61 contigs using MyPro pipeline. Assembly statistics were calculated using NGSQC toolkit (Table 2) (18). Total sequence length of 4,580,837 bases then annotated by PGAP (Prokaryotic Genome Annotation Pipeline, https://www.ncbi.nlm.nih.gov/genome/annota tion_prok/). This annotated data was submitted to NCBI and assigned the accession No.: MASN00000000 BioProject: PRJNA 327293, BioSample: SAMN05328039, Organism: Natrialba sp. SSL1 which has been validated (Table 3). This data when processed by Prokka for annotation generated 4476 genes; however BLAST analysis of these data did not match with the reference Natrialba genome (unpublished data). Therefore, it reveals that this annotation tool was found to be inappropriate for haloarchaeal genomes. The annotation by GenBank using PGAP pipeline generated 4272 genes, most of them matched with Natrialba spp. It was interesting to note that the genome sequenced contains genes for bacteriocin, bacterioopsin, amylase, phospholipase, proteases, etc.

Out of 4272 annotated genes, 4217 are CDS genes and total 55 RNA genes. These CDS genes contain 4121 coding genes, while 96 genes were considered as pseudogenes. The 55 RNA genes included 2 rRNA, 2 complete rRNA, 49 tRNA and 2 ncRNA's. The data is compared with other six Natrialba genomes sequenced (Table 4). Preliminary annotation, prediction of the number of subsystems, and pairwise BLAST comparisons of protein sets 
within different strains was performed using NCBI PGAP that deciphered 4048 proteins. These annotation details are provided at the web

sitehttps://www.ncbi.nlm.nih.gov/protein/?ter m=txid1869245 [Organism:noexp]. Natrialba SSL 1 contained single origin of replication (orc1/cdc6) while that of other halolalkaliphilic archaea contains multiple origins of replication. Two replication origins reported in Nab. magadii (20). The replication origin of Halobacterium salinarium R1 is delineated by a 31-bp inverted repeat that is flanked on one side by a Cdc6 homolog (orc7, $\mathrm{OE} 4380 \mathrm{~F})$. On the other side the repeat is flanked by a set of three genes (OE4377R, OE4376R, OE4374R) that are also found adjacent to the replication origin in Natronomonas pharaonis (Paul et al., 2008), Haloquadratum walsbyi (Oren, 1994), and Haloarcula marismortui (Ochsenreiter et al., 2002). These genes have no known function, but the positional conservation observed in all halophiles may indicate an involvement of the three proteins in the replication process. Natrialba SSL1 possesses 52 putative genes for transposes.

Haloalkaliphilic species cell wall containing acidic glycoprotein along with adaptive mechanism by accumulating inorganic cationic /organic neutral biomolecules. Halophilicarchaea maintains required water balance and osmotic pressure by pumping $\mathrm{Na}^{+}$ out and $\mathrm{K}^{+}$in antiporter. Natrialba SSL1 possess genes for $\mathrm{Na}+\mathrm{H}+$ antiporter, bile acid: sodium symporter, cation acetate symporter, glycine/betaine $\mathrm{ABC}$ transporter, peptide transporter observed at various locations. Natrialba SSL1 also contained genes encoding the biosynthesis of spermine as well as transporters for the uptake of amino acid, maltose, malonate and spermidine/putrescine, which may also provide protection at high-osmolarity. Thus, Natrialba SSL1 had multiple mechanisms for osmotic adaptation by intracellular accumulation of inorganic cations and organic solutes, charged organic compounds for osmotic adaptation. Depletion of molecular oxygen in a soda lake and similar saline environment could be a growth-limiting factor for aerobic chemoorganotrophic bacteria and archaea (Mirmohammadsadeghi et al., 2013). Some archaeal species accumulate intracellular gas vesicle that assist them to float on surface of salt water and help in oxidative respiration. Nab. magadii lacked genes related to those encoding the minor gas vesicle protein $(\mathrm{GvpC})$ and the regulators (GvpD and GvpE) (Xu et al., 2001). Interestingly Natrialba SSL1 possessed various genes encoding gas vesicle proteins like GvpA, GvpFL, GvpJ and GvpN, which indicates the presence of intracellular gas vesicle for buoyancy. Various genes encoding metal transport proteins and a putative copper/Zinc resistance protein also indicate survival in homeostatic mechanism for survival in harsh saline and alkaline environments.

Table.1 Taxonomy of recognized species within the genus Natrialba (as of April 2017)

\begin{tabular}{|l|l|}
\hline \multicolumn{2}{|l|}{ Family Natrialba Kamekura and Dyall-Smith 1995 gen. nov. } \\
\hline Species & Reference \\
\hline Natrialba magadii & (Tindall et al. 1984 )Kamekura et al. 1997, comb. nov. \\
\hline Natrialba asiatica & Kamekura and Dyall-Smith 1995 sp. nov. \\
\hline Natrialba aegyptia & corrig. Hezayen et al. 2001, sp. nov. \\
\cline { 1 - 1 } Natrialba chahannaoensis & Xu et al. 2001, sp. nov. \\
\cline { 1 - 2 } Natrialba hulunbeirensis & \\
\hline Natrialba taiwanensis & Hezayen et al. 2001, sp. nov. \\
\hline
\end{tabular}


Table.2 Assembly statistics of the Natrialba genome

\begin{tabular}{|l|r|}
\hline Total sequences & 61 \\
\hline Total bases & 4580837 \\
\hline Min sequence length & 391 \\
\hline Max sequence length & 526792 \\
\hline Average sequence length & 75095.69 \\
\hline Median sequence length & 16138 \\
\hline N25 length & 455572 \\
\hline N50 length & 292114 \\
\hline N75 length & 138183 \\
\hline N90 length & 68519 \\
\hline N95 length & 27066 \\
\hline As & $19.31 \%$ \\
\hline Ts & $19.22 \%$ \\
\hline Gs & $30.71 \%$ \\
\hline Cs & $30.76 \%$ \\
\hline A + T)s & $38.53 \%$ \\
\hline G + C)s & $61.47 \%$ \\
\hline Ns & $0.00 \%$ \\
\hline
\end{tabular}

Table.3 Genomic data analysis of Natrialba SSL1, ATCC 43988

\begin{tabular}{|c|c|}
\hline & NCBI \\
\hline Annotation Provider & $07-05-1616: 57$ \\
\hline Annotation Date & PGAP \\
\hline Annotation Pipeline & set; GeneMarkS+ \\
\hline Annotation Method & 3.3 \\
\hline Annotation Software revision & 4,276 \\
\hline Features Annotated & 4,222 \\
\hline Genes (total) & 4,126 \\
\hline CDS (total) & 4,126 \\
\hline Genes (coding) & 54 \\
\hline CDS (coding) & $2,1(5 \mathrm{~S}, 16 \mathrm{~S})$ \\
\hline Genes (RNA) & $2,1(5 \mathrm{~S}, 16 \mathrm{~S})$ \\
\hline rRNAs & 49 \\
\hline complete rRNAs & 2 \\
\hline tRNAs & 96 \\
\hline ncRNAs & 0 of 96 \\
\hline Pseudo Genes (total) & 32 of 96 \\
\hline Pseudo Genes (ambiguous residues) & 60 of 96 \\
\hline Pseudo Genes (frameshifted) & 15 of 96 \\
\hline Pseudo Genes (incomplete) & 9 of 96 \\
\hline Pseudo Genes (internal stop) & \\
\hline Pseudo Genes (multiple problems) & GRA; tRNA; nNA \\
\hline
\end{tabular}


Table.4 Comparison of basic data for the Natrialba genomes sequenced to date (Source: NCBI)

\begin{tabular}{|c|c|c|c|c|c|c|c|}
\hline & $\begin{array}{l}\text { Nab. } \\
\text { SSL1 }\end{array}$ & $\begin{array}{l}\text { Nab. } \\
\text { asiatica }\end{array}$ & $\begin{array}{l}\text { Nab. } \\
\text { aegyptia }\end{array}$ & $\begin{array}{l}\text { Nab. } \\
\text { chahannaeonsis }\end{array}$ & $\begin{array}{l}\text { Nab. } \\
\text { magadii* }\end{array}$ & $\begin{array}{l}\text { Nab. } \\
\text { taiwanensis }\end{array}$ & $\begin{array}{l}\text { Nab. } \\
\text { hulunbeirensis }\end{array}$ \\
\hline BioProject & PRJNA327293 & PRJNA174930 & PRJNA174929 & PRJNA174931 & NA & PRJNA174933 & PRJNA174932 \\
\hline $\begin{array}{l}\text { Length } \\
(\mathrm{Mb})\end{array}$ & 4.58 & 4.40 & 4.61 & 4.30 & 3.75 & 4.64 & 4.16 \\
\hline GC\% & 61.5 & 62.4 & 62.0 & 60.4 & 61.4 & 61.5 & 61.7 \\
\hline Contigs & 61 & 49 & 66 & 106 & NA & 70 & 48 \\
\hline$\%$ coding & 96.4 & 95.55 & 95.33 & 93.75 & 89.95 & 94.79 & 94.06 \\
\hline $\begin{array}{l}\text { Encoded } \\
\text { proteins }\end{array}$ & 4121 & 3995 & 4186 & 3765 & 3142 & 4136 & 3662 \\
\hline Genes & 4272 & 4181 & 4391 & 4016 & 3493 & 4363 & 3839 \\
\hline $\begin{array}{l}\text { Encoded } \\
\text { stable } \\
\text { RNAs }\end{array}$ & 55 & 54 & 58 & 54 & 55 & 50 & 54 \\
\hline
\end{tabular}

Fig.1 Recent satellite image of Sambhar lake, Rajasthan, India showing dark green and red coloration indicating the mass bloom of haloalkaliphilic algae and archaea. (Source: Google maps). It also shows the shrinking of lake area

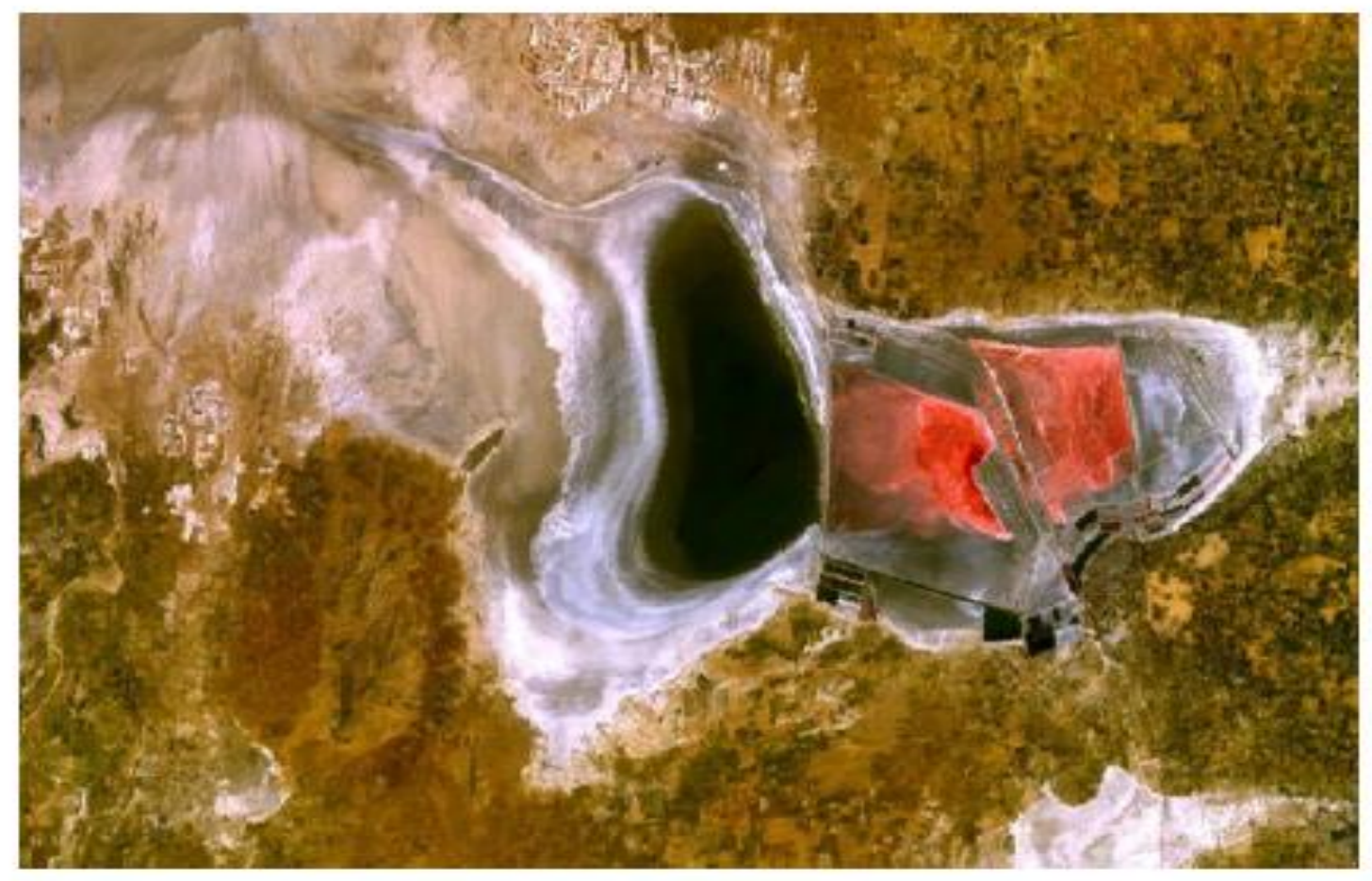


Fig.2 Phylogenetic tree of Natrialba SSL1 (ATCC 43988) showing relationship with other species constructed using MEGA6

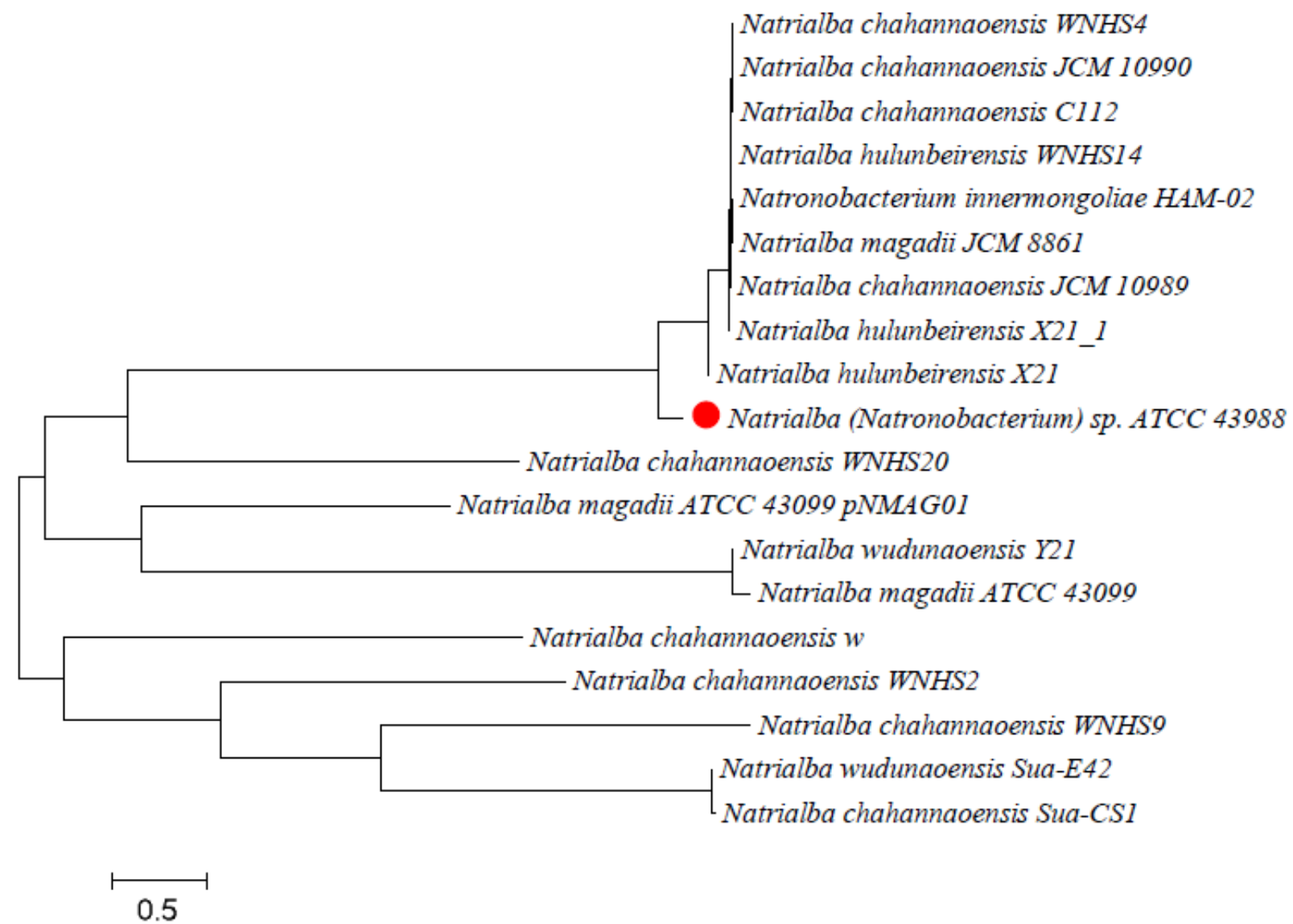

Presence of DNA damage and repair proteins RadA and RadB indicate survival strategy against UV exposure.

Halophilic and haloalkaliphilic archaea thrive on different nutritional demand (Gupta et al., 2015). The analysis of the genome sequence of Natrialba SSL1 provides information for their ability to assimilate $\mathrm{C} 4, \mathrm{C} 5$ and $\mathrm{C} 6$ carbon compounds. Interestingly, the species also survives by assimilating noncarbohydrate sources like proteins and fats. Furthermore, genes encoding putative enzymes for archaeal modified pathways of gluconeogenesis and glycolysis as well as those of ribose metabolism and the tricarboxylic acid cycle were present in Natrialba SSL1. Genes that deciphered to putative enzymes for glycerol utilization, branched chain and aromatic amino acid catabolism, proteasome synthesis, $\mathrm{ABC}$ transporters, co-factor molybdopterin biosynthesis protein, cationic antiporter, symporter and transporter proteins were also present.

Extremozymes from archaea have biotechnological and industrial importance. In Natrialba SSL1 genes encoding for serine protease, cystein protease, metallo-protease, lipase, phospholipase, alpha-amylase and cytoplasmic alpha-amylase have been found to be present. The production of halocin by Natrialba SSL1 has been reported (Upasani, 1988), this is also substantiated by the evidence for the genes for the same in the genome. 
There are several reports on the presence of phages in haloarchaea (Siddaramappa et al., 2012; Schnabel et al., 1982; Torsvik et al., 1974). The genes encoding phage tail and base plate proteins indicate the lysogenic nature of Natrialba SSL1. The phage encoded proteins have also been reported in $\mathrm{Hbt}$. salinarum R1, Halobacterium NRC-1, Hqr. walsbyi DSM 16790, Haloterrigena turkmenica DSM 5511, Nmn. moolapensis, Nmn. pharaonis DSM 2160 and Nab. magadii. Natrialba SSL 1 genome also contains genes for rhodopsins and lycopene biosynthesis. These genes are involved in unique phototphosphorylation and imparting colour to this haloarchaeon.

In conclusion, genome sequencing of the first haloalkaliphilic archaeon from Sambhar lake, India Natrialba SSL1 (ATCC 43988) revealed that it is genetically distinct with that of Nab. magadii species, as it possesses genes for intracellular gas vesicle and trehalose synthesis. Presence of genes encoding for phage base plate and tail proteins suggests further studiesto isolate and characterize the bacteriophage. The whole genome sequence data has been deposited with GenBank accession No.: MASN00000000 BioProject: PRJNA327293. Further, comparative genomic and proteomic studies will help in understanding the evolution of this extremophile and its biotechnological applications.

\section{Acknowledgement}

The authors are grateful to M. G. Science Institute (Ahmedabad Education Society) and IBio Analysis Pvt. Ltd., for providing lab facilities. The assistance by Harshil Bhatt for phylogenetic analysis is also acknowledged.

\section{References}

Berquist, B.R., and Das Sarma, S. 2003. An archaeal chromosomal autonomously replicating sequences element from extreme halophiles, Halobacterium sp. Strain NRC-1, J. Bacteriol., 185: 59595966

Berquist, B.R., Soneja, J.A., DasSarma, S. 2005. Comparative genomic survey of information transfer systems in two diverse extremely halophilic archaea, Halobacterium sp. strain NRC1 and Haloarcula marismortui. In Adaptation to Life at High Salt Concentrations in Archaea, Bacteria, and Eukarya. Edited by GundeCimerman N, Oren A, Plemenita A. Dordrecht,

The Netherlands: Springer, 148-182.

Bolhuis, H., Palm, P., Wende, A., Falb, M., Rampp, M., Rodriguez-Valera, F., Pfeiffer,

F., Oesterhelt, D. 2006. The genome of the square archaeon Haloquadratum walsbyi: life at the limits of water activity. BMC Genomics, 7: 169.

Cuadros-Orellana, S., Pohlschröder, M., Durrant, L. R. 2006. Isolation and characterization of halophilic archaea able to grow in aromatic compounds. Int. Biodeter. Biodeg., 57: $151-154$.

Emble, T. M. 1991. The linear PCR reaction: a simple and robust method for sequencing amplified rRNA genes, Lett. Appl. Microbiol., 13: 171-174

Falb, M., Muller, K., Konigsmaier, L., Oberwinkler, T., Horn, P., von Gronau, S.,Gonzalez, O., Pfeiffer, F., BornbergBauer, E., Oesterhelt, D. 2008. Metabolism of halophilicarchaea. Extremophiles, 12: 177-196.

Falb, M., Pfeiffer, F., Palm, P., Rodewald, K., Hickmann, V., Tittor, J. \& Oesterhelt, D. 2005. Living with two extremes: conclusions from the genome sequence of Natronomonas pharaonis. Genom. Res., 15: 1336-1343 
Gupta, R. S., Naushad, S. \& Baker, S. 2015. Phylogenomic analyses and molecular signatures for the class Halobacteria and its two major clades: a proposal for division of the class Halobacteria into an emended order Halobacteriales and two new orders, Haloferacales ord. nov., and Natrialbales ord. nov., containing the novel families Haloferacaceae fam. nov., and Natrialbaceae fam. nov. Int. J. Syst. Evol. Microbiol., 65: 10501069

Hezayen, F. F., Rehm, B. H. A., Tindall, B. J. \& Steinbu" chel, A. 2001. Transfer of Natrialba asiatica B1T to Natrialba taiwanensis sp. nov. and description of Natrialba aegyptiaca sp. nov., a novel extremely halophilic, aerobic, nonpigmented member of the Archaea from Egypt which produces extracellular poly(glutamic acid). Int. J. Syst. Evol. Microbiol., 51: 1133-1142.

Kamekura, M. and Dyall-Smith, M. L. 1995. Taxonomy of the family Halobacteriaceae and the description of the two new genera Halorubrobacterium and Natrialba. J. Gen. Appl. Microbiol., 41: 333-350

Kamekura, M., Dyall-Smith, M. L., Upasani, V., Ventosa, A. \& Kates, M. 1997. Diversity of alkaliphilic halobacteria: proposals for the transfer of Natronobacterium vacuolatum, Natronobacterium magadii, and Natronobacterium pharaonis to the genus Halorubrum, Natrialba, and Natronomonas gen. nov., respectively, as Halorubrum vacuolatum comb. nov., Natrialba magadii comb. nov., and Natronomonas pharaonis comb. nov., respectively. Int. J. Syst. Bacteriol., 47: 853-857

Kates, M. 1993. Membrane lipids of extreme halophiles: biosynthesis, function and evolutionary significance. Experientia, 49: $1027-1036$

Kennedy, S.P., Ng, W.V., Salzberg, S.L., Hood, L., \& DasSarma, S. 2001. Understanding the adaptation of Halobacterium species NRC-1 to its extreme environment through computational analysis of its genome sequence. Genome Res., 11: 1641-1650

Liao, Yu.C., Lin H.H., Sabharwal, A., Haase, E.M. \& Scannapieco, F. A. 2015. MyPro: A seamless pipeline for automated prokaryotic genome assembly and annotation. J. Microbiol. Methods, 113: 72-74

McGenity, T. J., Renia, T., Gemmel, T. and Grant, W. D. 1998. Proposal of a new halobacterial genus Natrinema gen. nov., with two species Natrinema pellirubrum nom. nov. And Natrinerna pallidum nom. nov. Int. J. System. Bacteriol., 48: 1187-1196

Mirmohammadsadeghi, H., Abedi, A., Mohmoudpour, H. A., Akbari, V. 2013. Comparison of field methods for extraction of genomic DNA from a marine Archaea, Pyrococcus furiosus, Pak. J. Med. Sci., 29(1): 309-394

Ochsenreiter, T., Pfeifer, F. \& Schleper, C. 2002. Diversity of Archaea in hypersaline environments characterized by molecular-phylogenetic and cultivation studies. Extremophiles, 6: 267-274.

Oren, A. 1994The ecology of the extremely halophilicarchaea. FEMS Microbiol. Rev., 13: 415-439

Patel, R.K. \& Jain, M. 2012. NGS QC Toolkit: A toolkit for quality control of next generation sequencing data. PLoS ONE, 7(2): e30619.

Paul, S., Bag, S. K., Das, S., Harvill, E. T., Dutta, C. 2008. Molecular signature of hypersaline adaptation: insights from genome and proteome composition of 
halophilic prokaryotes. Genom. Biol., 9: R70.

Schnabel, H. Zillig, W., Pfaffle, M., Schnabel,R., Michel,H., \& Delius, H., 1982. Halobacterium halobium phage $\varnothing \mathrm{H}$. The EMBO J., 1(1): 87-92

Siddaramappa, S., Challacombe, J. F., DeCastro, R. E., Pfeiffer, F., Sastre, D. E., Giménez, M. I., Paggi, R. A., Detter, J. C., Davenport, K. W., Goodwin, L. A., Kyrpides, N., Tapia, R., Pitluck, S., Lucas, S., Woyke, T., Julie, A. Maupin \&Furlow, J. A. 2012. A comparative genomics perspective on the genetic content of the alkaliphilic haloarchaeon Natrialba magadii ATCC 43099T. BMC Genomics, 13: 165

Sreeramulu, K., Schmidt, C. L., Schafer, G. \& Anemuller, S. 1998. Studies of the electron transport chain of the euryarcheon Halobacterium salinarum: indications for a type II NADH dehydrogenase and a complex III analog. J. Bioenerg. Biomemb., 30: 443-453

Tindall, B.J., Rose, H.N.M., Grant, W. D. 1984.Natronobacterium gen. nov. and Natronococcus gen. nov. Two new genera of halolalkaliphilic Archaebacteria, System. Appl. Microbiol., 5: 41-57

Torsvik, T. \& Dundas, I.D. 1974. Bacteriophage of Halobacterium salinarium, Nature, 248(5450): 680 681.
Upasani, V. N., Desai, S. G., Moldoveanu, N. \& Kates, M. 1994. Lipids of extremely halophilic archaeobacteria from saline environments in India: a novel glycolipid in Natronobacterium strains. Microbiol., 140: 1959-1966

Upasani, V.N. 1988. Studies on halophilism. $\mathrm{Ph}$. D. thesis, Gujarat University, India.

Upasani, V.N. 2008. Microbiological studies on Sambhar Lake (Salt on Earth) Rajasthan, India. Proceedings of TAAL 2007: The 12th World Lake Conference, 448-450.

Upasani, V.N., \& Desai, S.G. 1990. Sambhar Salt Lake; chemical composition of brines and studies on haloalkaliphilic archaeobacteria. Arch. Microbiol., 154: 589-593

Ventosa, A. 2006. Unusual micro-organisms from unusual habitats: hypersaline environments In Logan, N.A., LappinScott, H. M., \& Oyston PCF (eds.). Prokaryotic diversity: mechanisms and significance. New York: Cambridge University Press, 223-254 pp.

Xu, Y., Wang, Z., Xue, Y., Zhou, P., Ma, Y., Ventosa, A. \&Grant, W.D. 2001 Natrialba hulunbeirensis sp. nov. and Natrialba chahannaoensis sp. nov., novel haloalkaliphilic archaea from soda lakes in Inner Mongolia Autonomous Region, China. Int. J. System. Evol. Microbiol., 51: 16931698.

\section{How to cite this article:}

Kalambe, G.N., P.M. Chandarana, V.M. Tanavade and Upasani, V.N. 2017. Draft Genome Sequence of a Haloalkaliphilic archaeon: Natrialba sp. SSL1 (ATCC 43988) Isolated from Sambhar Salt Lake, India. Int.J.Curr.Microbiol.App.Sci. 6(5): 2399-2408. doi: https://doi.org/10.20546/ijcmas.2017.605.268 